\title{
Glaucoma of the Inner Ear Vis-a-Vis Endolymphatic Hydrops: an Updated Imaging Algorithm
}

\author{
Khizer Razak, Surbhi Gupta and GL Meena* \\ Department of Radiodiagnosis, SP Medical College, India
}

Submission: November 02, 2017; Published: November 27, 2017

"Correspondence Address: Gl Meena, Senior professor \& Head, Dept of Radiodiagnosis, Sardar Patel Medical College, Bikaner 334003, Rajasthan, India, Email: meenabkn@yahoo.co.in

\begin{abstract}
Aims \& Objectives: Menières disease is a disease of the inner ear characterised by recurrent episodes of fluctuating sensorineural hearing loss, vertigo, pulsatile tinnitus and aural fullness. Diagnosis is made by clinical characteristics and clinical/physiological testings, but in many cases a definite diagnosis of Menières disease is not possible. Objective of this study was to demonstrate the quantitative evaluation of endolymphatic hydrops in Menières disease patients, compared to an evaluation done semi-quantitatively.

Materials \& Methods: This prospective clinical study was conducted at the Prince Bijey Singh Memorial Hospital, Bikaner, Rajasthan including $\mathrm{n}=10$ patients with definite and $\mathrm{n}=1$ patient with possible diagnosis of Menière's disease. As negative control an asymptomatic subject was examined the same way. The imaging was performed on a 1.5tesla MR imaging unit (Philips Achieva, Philips Medical Systems, Best, NL) using a 16-channel array head and neck coil.

Conclusion: Endolymphatic Hydrops MRI is a highly recommendable diagnostic tool to evaluate endolymphatic hydrops in Menière's disease. Our study shows that the existing semi quantitative grading systems are highly accurate, but special anatomical conditions (e.g. intralabyrinthine tumors) should be additionally evaluated by quantitative post-processing methods.
\end{abstract}

Keywords: Hydrops; Imaging; MRI; Algorithm

\section{Introduction}

Menières disease is a highly stressful and personally restricting disorder of the inner ear [1]. Diagnosis is made by clinical characteristics and clinical/physiological testings, but in many cases a definite diagnosis of Menières disease - is not possible [2,3]. The recently established Endolymphatic Hydrops MRI (EH-MRI) by use of i.v.-application of Gadolinium-based contrast agents allows the in-vivo diagnosis of Menières disease Naganawa et al. [4]. The already prevalent analysis done semi-quantitatively, objective grading systems may be inaccurate in lieu of therapy monitoring and have recently shown lacunae.

\section{Materials \& Methods}

This prospective clinical study was conducted at the Prince Bijey Singh Memorial Hospital, Bikaner, Rajasthan including $\mathrm{n}=10$ patients with definite and $\mathrm{n}=1$ patient with possible diagnosis of Menière's disease. As negative control an asymptomatic subject was examined the same way. The patient's mean age was 35 to 75 years (54.91 \pm 14.2 years), 7 patients were female and 4 male. 4 hours before MR measurements intravenous application of a single dose 0 mniscan ${ }^{\circledR}(0.2 \mathrm{ml} / \mathrm{kg}$ or $0.1 \mathrm{mmol} / \mathrm{kg}$ body weight) was performed (Figure 1). The imaging was performed on a 1.5tesla MR imaging unit (Philips Achieva) using a 12-channel array head and neck coil. Endolymphatic hydrops was graded by two different radiologists in consensus-procedure according to the criteria of Nakashima, Naganawa et al. [5]. After the examination, a survey consisting of 8 questions was conducted for evaluation of patient acceptance and satisfaction. Institutional review board approval was obtained for this study.

\section{Results}

MRI was carried out on average 4 hours after intravenous-injection of a standard-dose Omniscan $(0.2$ $\mathrm{ml} / \mathrm{kg}$ or $0.1 \mathrm{mmol} / \mathrm{kg}$ body weight). The measurements done quantitatively of the endolymph showed a mean volume of the cochlear labyrinth of $104 \mu \mathrm{l}$ and a mean volume of the vestibular labyrinth of $165 \mu \mathrm{l}$. The total labyrinth volume was $265 \mu \mathrm{l}$. The difference was statistically significant $p=0.025$; (Figure 2 ). The affected 
inner ears showed this accentuated volume increase as well as the side without endolymphatic hydrops. Symptoms occurred on the left ear in 5 cases (right ear 4 cases) and in one case both ears were affected [6].

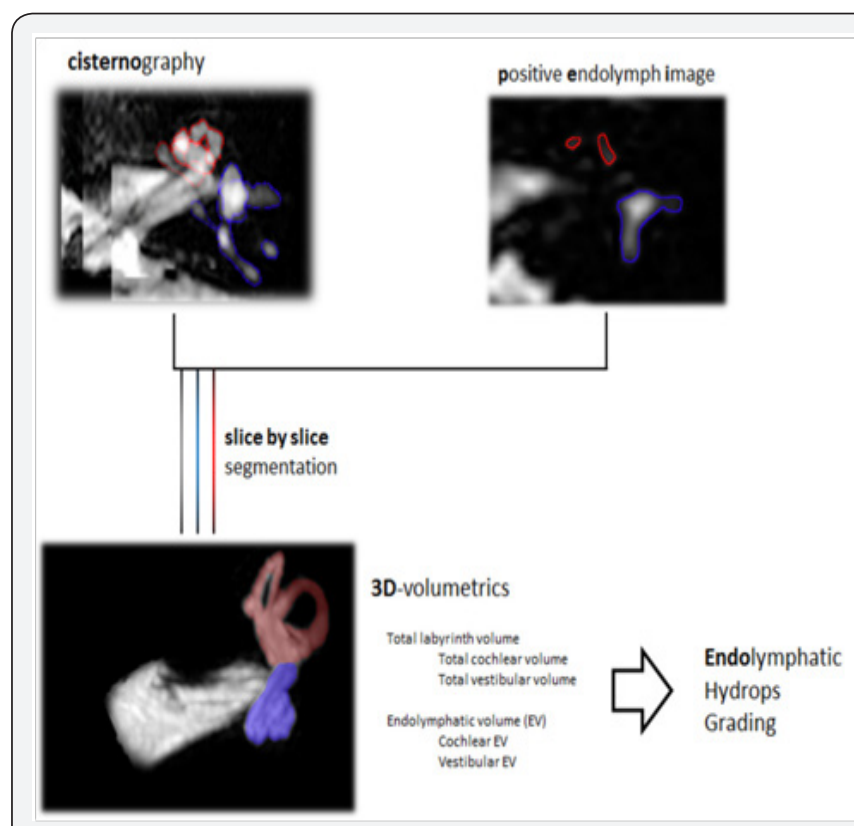

Figure 1: Volumetric assessment of labyrinth and endolymphatic space: Positive Endolymphatic Image (PEI) and T2DRIVECisternography was segmented slice-by slice.

Semi-quantitative analysis for the total of $\mathrm{n}=$ 20 cochlear structures in 12 inner ears no cochlear hydrops was detected, $n=4$ inner ear presented with a minimal degree of cochlear hydrops and $n=6$ inner ears were effected with significant degree by cochlear endolymphatic hydrops. The semi quantitative analysis of the endolymphatic sac delivered 3 inner ears with mild cochlear hydrops, $n=6$ with significant degree of cochlear hydrops and 13 patients had no relevantly dilated endolymphatic cul-de-sac. The correlation coefficient $r$ between both methods was $r=1$ for the right ear and $r=$ 0.95 for the left ear.

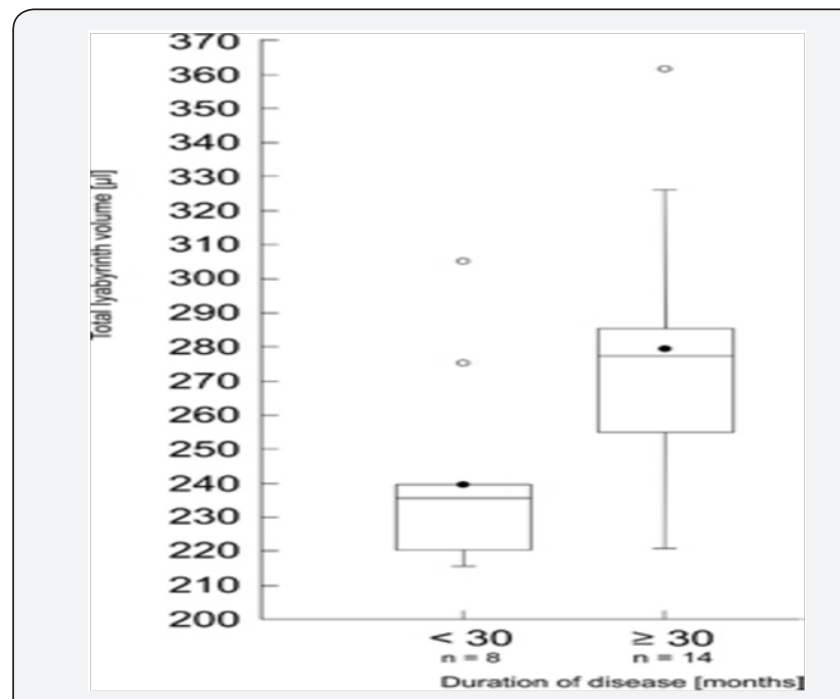

Figure 2: Total labyrinth size (y-axis) in dependence of the duration of the disease (x-axis). The difference between both groups was considered significant $(p=0.025)$.

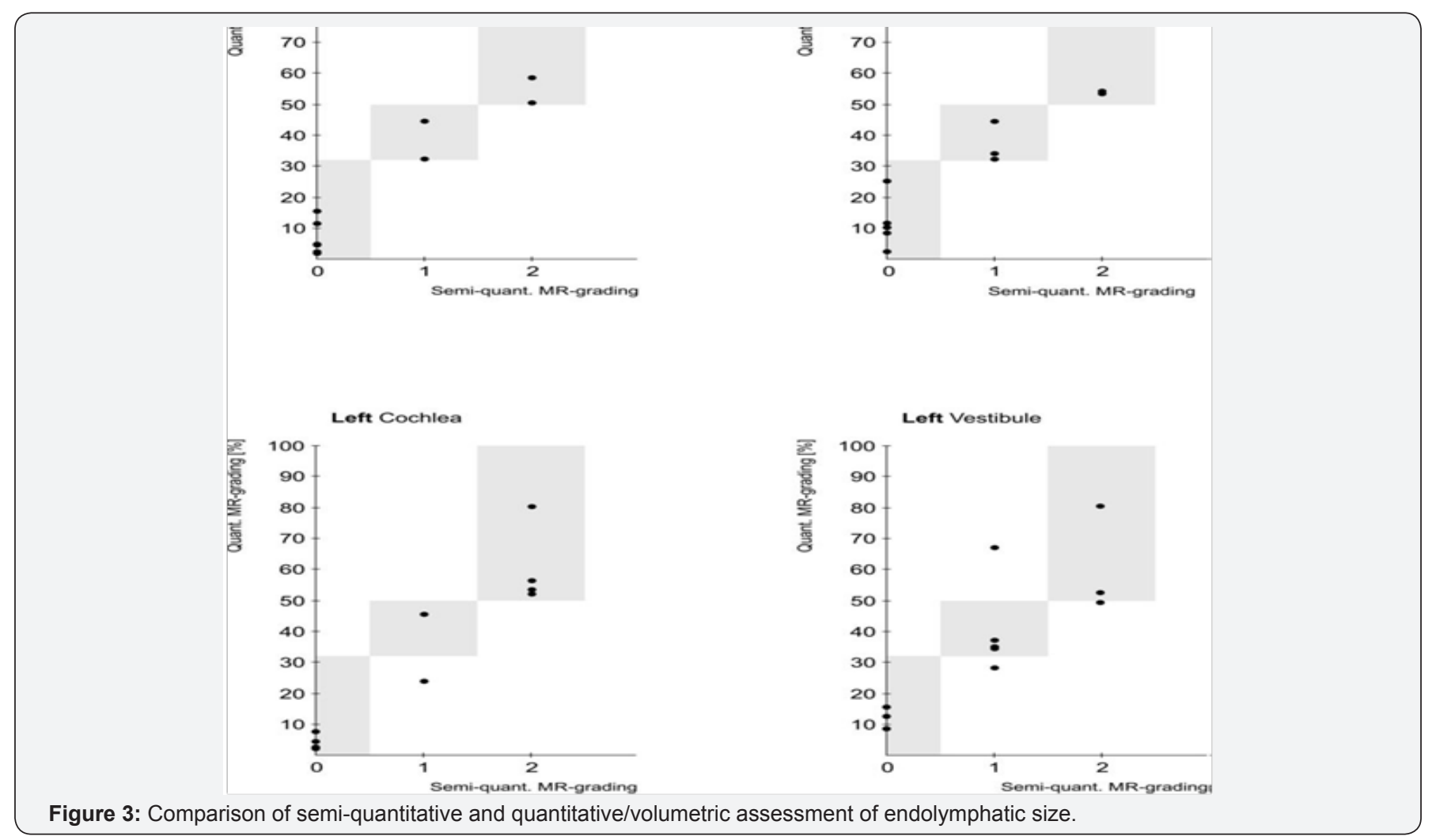


The evaluated analysis semiquantitavely of the vestibule showed the following results: $n=7$ inner ears showed a mild degree of vestibular endolymphatic hydrops, $\mathrm{n}=7$ a significant vestibular $\mathrm{EH}$ and 8 inner ears showed no relevant EH Correlation coefficients between semi-quantitative and quantitative analysis were $r=1$ for the right and $r=0.73$ for the left vestibular structures (Figure 3). We detected no statistical significant difference between both methods.

\section{Patient Acceptance Testing}

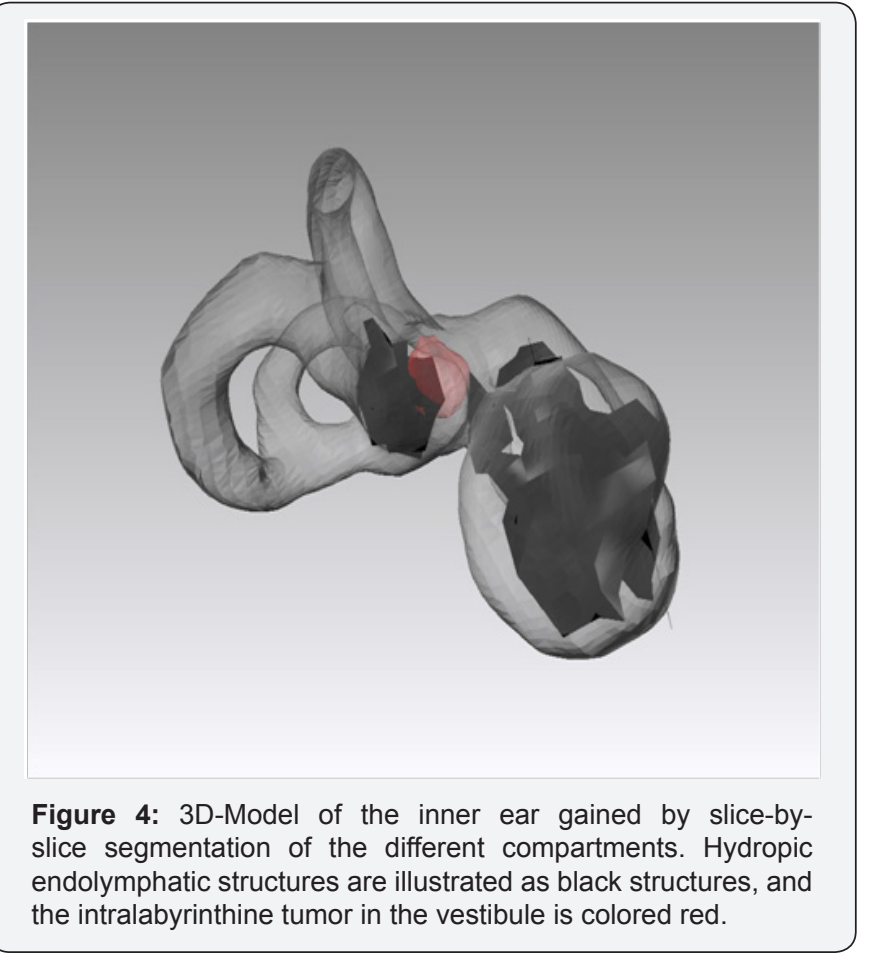

8 from 11 patients participated in the survey. Due to the ongoing stress and strain of the examination undertaken a mean value of 3 (in a scale of 1 to 10 with $1=$ nonstressful, 5=mid range and $10=$ extremely stressful) was made, no patient had any problems with the intravenous -application of the contrast agent. The personal benefit for the patients was high. All patients felt confident that the results of the examination have an impact on therapy and course of the disease. Moreover, all of the included subjects would recommend Endolymphatic Hydrops MRI to other patients (Figure 4).

\section{Conclusion}

MRI is a highly efficient diagnostic tool to evaluate hydrops in Menière's disease. Our study shows that the already compliant quantitative analyses are highly accurate, but certain necessary conditions (e.g., schwannoma) should be additionally evaluated by semiquantitative post-procedural methods. The importance of patient satisfaction and accessability and the high acceptance of CE MRI-examinations should be taken into account in the upcoming years to succor our fellow otologists.

\section{References}

1. Homann G, Fahrendorf D, Niederstadt T, Nagelmann N, Heindel W, et al. (2014) HR 3 Tesla MRI for the Diagnosis of Endolymphatic Hydrops and Differential Diagnosis of Inner Ear Tumors - Demonstrated by twei Cases with Similar Symptoms. Rofo 186(3): 225-229.

2. Krombach GA, van den Boom M, Di Martino E, Schmitz-Rode, Westhofen M, et al. (2005) Computed tomography of the inner ear: Size of anatomical structures in the normal temporal bone and in the temporal bone of patients with Menière's disease. Eur Radiol 15(8): 1505-1513.

3. Bakthavachalam S, MacDonald CB, Gira J, Caruthers SD, Jara H, et al. (1998) Inner ear volumetric measurements using high-resolution 3D T2-weighted fast spin-echo MR imaging: Initial experience in healthy subjects. AJNR 19(10): 1819-1822.

4. Naganawa S, Yamazaki M, Kawai H, Bokura K, Sone M, et al. (2012) Imaging of Endolymphatic and Perilymphatic Fluid after intravenous Administration of Single-Dose Gadodiamide. Magn Reson Med Sci 11(2): 145-150.

5. Naganawa S, Yamazaki M, Kawai H, Bokura K, Sone M, et al. (2012) Imaging of Menière's Disease after intravenous Administration of Signle-Dose Gadodiamide: Utility of Subtraction Images with different Inversion Time. Magn Reson Med Sci 11(2): 145-150.

6. Nakashima T, Naganawa S, Pyykko I, Gibson WP, Sone M, et al. (2009) Grading of Endolymphatic Hydrops using Magnetic Resonance Imaging. Acta Otolaryngol Suppl 560: 5-8.
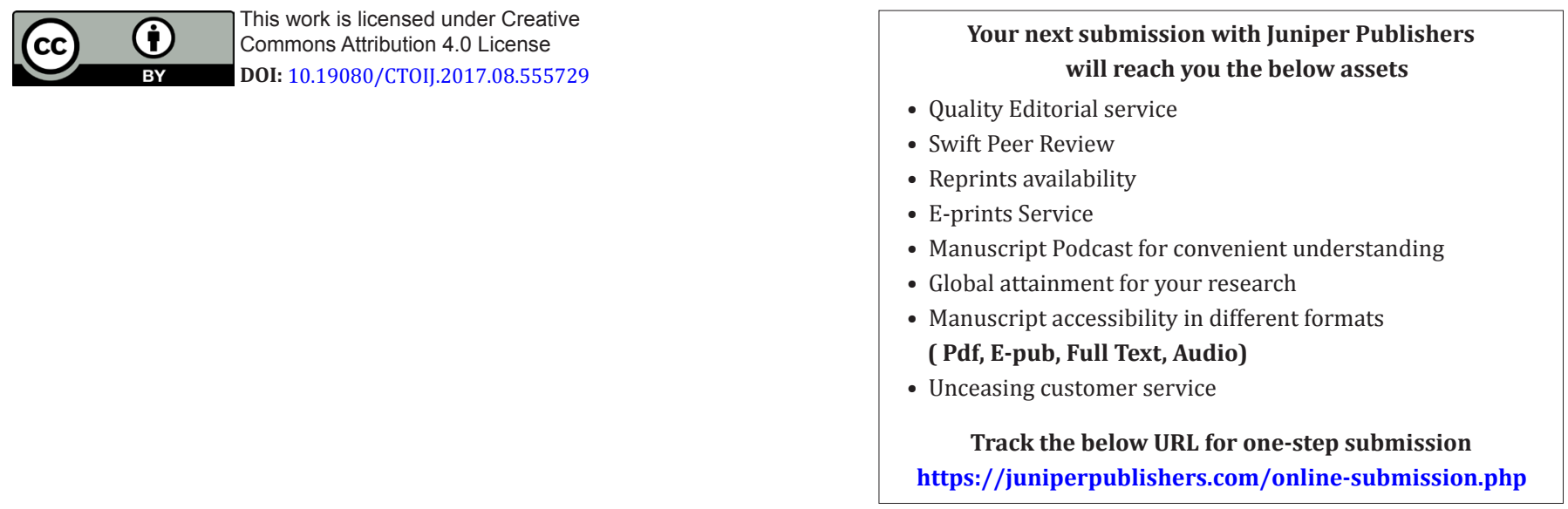